Revue

Revue de l'histoire des religions

de Ihistoire des religions

$3 \mid 2018$

Varia

\title{
1832-1835, moment mennaisien. L'esprit croyant des années 1830
}

1832-1835, a Mennaisian Moment. The Believing Spirit of the 1830s

Sylvain Milbach

(2) OpenEdition

Journals

Édition électronique

URL : http://journals.openedition.org/rhr/8943

DOI : $10.4000 /$ rhr.8943

ISSN : 2105-2573

Éditeur

Armand Colin

Édition imprimée

Date de publication : 1 septembre 2018

Pagination : 451-484

ISBN : 978-2-200-93188-9

ISSN : 0035-1423

Référence électronique

Sylvain Milbach, «1832-1835, moment mennaisien. L'esprit croyant des années 1830 », Revue de I'histoire des religions [En ligne], 3 | 2018, mis en ligne le 01 septembre 2020, consulté le 13 janvier 2021. URL : http://journals.openedition.org/rhr/8943 ; DOI : https://doi.org/10.4000/rhr.8943 


\section{2-1835, moment mennaisien L'esprit croyant des années 1830}

La condamnation par Rome des idées de Lamennais a le plus souvent été étudiée pour sa portée politique et l'accent a été mis sur l'encyclique Mirari vos (1832). La seconde encyclique, Singulari nos (1834), est restée surtout le motif pour expliquer le "drame mennaisien». La présente contribution propose un double déplacement d'analyse : de la condamnation des idées politiques de Lamennais (1832) à celle de sa philosophie (1834); du drame mennaisien au désarroi d'une génération qui en avait subi directement ou indirectement l'influence. Ce moment mennaisien ne saurait donc être réduit au spectaculaire retournement du célèbre apologiste catholique, mais caractérise une configuration religieuse singulière, inscrite dans les scansions croyantes $d u X_{X}^{e}$ siècle qui marquèrent souvent les périodes post-révolutionnaires.

\section{2-1835, a Mennaisian Moment. The Believing Spirit of the 1830s.}

Rome's condemnation of Lamennais' ideas has been most often studied for its political significance, with the emphasis placed on the encyclical Mirari vos (1832). The second encyclical, Singulari nos (1834), has remained above all the key document for explaining the "Mennaisian drama." This paper proposes a double shift in the analysis : from the condemnation of Lamennais' political ideas (1832) to that of his philosophy (1834); from the Mennaisian drama to the dismay of a generation that had been directly or indirectly influenced by his thought. This Mennaisian moment cannot be reduced to the spectacular reversal of the famous Catholic apologist, but characterizes a singular religious configuration, inherent in the nineteenth-century believers' readings that frequently marked post-revolutionary periods. 
La condamnation du mennaisianisme par Rome - en deux temps : Mirari vos, 15 juillet 1832, et Singulari nos, 25 juin 1834 a surtout été étudiée pour rendre compte de l'évolution personnelle de Lamennais ${ }^{1}$. Quoique liées, ces deux encycliques sont de nature différente: Mirari vos condamne les propositions libérales de L'Avenir, et est inscrite ordinairement comme une étape dans le tournant intransigeant de l'Église catholique; Singulari nos condamne les Paroles d'un croyant, donc la personne de Lamennais, et provoque sa sortie de l'Église catholique. On se propose de relire la portée historique de ces deux encycliques en déplaçant un peu la focale, c'est-à-dire en ne se souciant pas du «drame mennaisien » qui a obnubilé les biographes, mais plutôt de la configuration politico-religieuse intimement liée à l'onde révolutionnaire et dont ce « drame » est une manifestation paroxystique.

Depuis les invitations de Maurice Agulhon, les conséquences de la révolution de 1830 ont été largement réinvesties et réévaluées ${ }^{2}$. Toutefois, dans l'ordre religieux, les débuts de la monarchie de Juillet sont le plus souvent présentés sous l'angle de l'anticléricalisme, le changement de régime donnant effectivement lieu dans ce domaine à des explosions spectaculaires bien connues. Or, à l'heure où sont mûries et publiées les Paroles, entre 1832 et 1834 , la question religieuse a pris de nouvelles formes, dans les débats de l'élite spécialement, et la révolution de 1830 a été suivie d'interrogations religieuses confessées benoîtement ou brocardées par les contemporains ${ }^{3}$. Les contaminations entre les

1. Parmi les nombreuses biographies de Lamennais et une bibliographie foisonnante, on renverra en priorité à : Guido Verucci, Félicité Lamennais : dal cattolicesimo autoritario al radicalismo democratico, Napoli, nella sede dell'Istituto, 1963. Pour une approche historiographique, je me permets de renvoyer à : Sylvain Milbach, «Lamennais : "Une vie qui sera donc à refaire plus d'une fois encore". Parcours posthumes », Le Mouvement social, ${ }^{\circ} 246$, janviermars 2014, p. 75-96.

2. Citons : Patrick Harismendy (dir.), La France des années 1830 et l'esprit de réforme, Rennes, PUR, 2006 ; Sylvie Aprile, Jean-Claude Caron et Emmanuel Fureix, La liberté guidant le peuple. Les révolutions de 1830 en Europe, Seyssel, Champ Vallon, 2013.

3. Par exemple et respectivement: Marie d'Agoult, Mémoires, Paris, Mercure de France, 1990, t. 1, p. 282-284 ; Théophile Gautier, Mademoiselle de Maupin, [1835 ; édition GF, préface, p. 27-28]. 
spéculations religieuses, le mouvement des idées et les convictions politiques et sociales dans la première moitié du XIX ${ }^{e}$ siècle n'ont pas été ignorées des historiens ${ }^{4}$, les plaçant parfois dans la tradition illuministe $^{5}$ ou le renouveau ésotérique ${ }^{6}$, mais sans toujours en suivre les pulsations, les reconfigurations et les ramifications ${ }^{7}$. Le moment 1848 a souvent retenu à juste titre l'attention comme temps fort, mais il exista aussi un «moment $1830 »$, comme le suggérait Bernard Plongeron qui le plaçait sous l'inspiration d'un «souffle messianique ${ }^{8}$, et qu'Henri de Lubac qualifiait de «grande explosion d'un prophétisme métaphysico-social »'. Bien que préparant dans une certaine mesure l'esprit quarantehuitard, ce «moment» s'en distingue par la plus grande diversité que revêtit la question religieuse. Pour bien en saisir la nature, il convient de remettre en perspective les ambiguités de la position de Rome face à Lamennais en 1832, puis de comprendre la portée des Paroles en tenant compte avant tout de leur réception. Alors il est possible de saisir le «moment mennaisien » en déplaçant la question de son cas personnel vers les interrogations d'une génération, et de Mirari vos vers Singulari nos, c'est-à-dire de la condamnation politique vers le coup d'arrêt philosophique.

4. Récemment: Jérôme Grondeux, «Réflexions sur un rêve ancien : les religions de l'avenir », Romantisme, 2013/4, p. 33-43. Les historiens de la littérature et les historiens anglo-saxons ont été plus sensibles à la configuration religieuse des années 1830. Citons: Paul Bénichou, Le temps des prophètes. Doctrines de l'âge romantique, Paris, Gallimard, 1977 ; Brian Juden, Traditions orphiques et tendances mystiques dans le romantisme français, Paris, Klincksiek, 1971. Franck Paul Bowman se distingue spécialement. Citons : Le Christ des barricades, Paris, Cerf, 1987.

5. Auguste Viatte, Les sources occultes du romantisme, Paris, Honoré Champion, 1965 [1928], 2 vol.

6. Jean-Pierre Laurant, L'ésotérisme chrétien au XIXe siècle, Paris, L’Âge d'Homme, 1992.

7. Se reporter à l'analyse de Guillaume Cuchet, «L'histoire au noir de Philippe Muray. Le XIX siècle à travers les âges entre littérature et histoire ", Romantisme, 2016/3, p. 138-160.

8. Bernard Plongeron, «Le christianisme comme messianisme social», Jean-Marie Mayeur et al. (dir.), Histoire du christianisme, t. 10, Paris, Desclée, 1997, p. 837-905.

9. Henri de Lubac, La postérité spirituelle de Joachim de Flore, Paris, Cerf, 2014, p. 419 et suiv. 


\section{DEUX ENCYCLIQUES, UNE CONDAMNATION EN DEUX TEMPS}

Après une consultation en décembre 1831 sur l'opportunité de répondre à la demande pressante de Lamennais et de ses amis venus à Rome chercher l'approbation des doctrines de L'Avenir, un premier examen par une commission de cinq consulteurs ${ }^{10}$ fut organisé en juillet 1832 et décida du principe d'une encyclique ${ }^{11}$. Un second examen eut lieu après sa publication, en février 1833, sur la base d'une censure, réunissant cinquante-six propositions hétérodoxes, réalisée sous la direction de $\mathrm{Mgrd}^{\prime} \mathrm{Astros}^{12}$, archevêque de Toulouse, et donna lieu à un bref du 8 mai 1833 à cet archevêque. Cet examen, sur le fond identique au premier, mérite une attention particulière notamment à cause du rapport synthétique et méthodique de Mgr Frezza, une pièce maîtresse de ce dossier, et contribue à la compréhension des motivations du Saint-Siège.

\section{a. Les motifs des encycliques}

En première analyse, l'encyclique de 1832 condamne les «libertés devenues nécessaires au monde », suivant la formule de L'Avenir et c'est ce que retient en priorité l'historiographie: Mirari vos rejette les libertés issues de la Révolution ${ }^{13}$. Toutefois,

10. Le R. P. Rozaven, assistant de la Compagnie de Jésus pour la France; le P. Orioli, franciscain, consulteur de la congrégation de l'Index; Mgr Frezza, secrétaire de la Congrégation des affaires ecclésiastiques extraordinaires; Mgr Soglia Ceroni, de la même Congrégation ; et un consulteur resté anonyme, peut-être Jabalot, supérieur des dominicains. Si on excepte peut-être Orioli, qui avait traduit en italien la Défense de l'Essai sur l'indifférence, cette commission était bien moins favorable à Lamennais que celle de décembre 1831 où figurait au moins un de ses amis déclarés, quoique critique contre L'Avenir, le P. Ventura, supérieur des Théatins.

11. Marie-Joseph Le Guillou et Louis Le Guillou (éd.), La condamnation de Lamennais, Paris, Beauchesne, 1982. La plupart des documents évoqués dans la suite du propos sont issus, sauf mention contraire, de cet ouvrage qui reproduit le dossier Lamennais conservé dans les Archives de la Congrégation des affaires ecclésiastiques extraordinaires.

12. Paul Droulers, Action pastorale et problèmes sociaux sous la Monarchie de Juillet chez Mgr d'Astros : archevêque de Toulouse, censeur de La Mennais, Paris, J. Vrin, 1954

13. Pour une mise en perspective générale : Roger Aubert, «L'enseignement du magistère ecclésiastique au $\mathrm{XIX}^{\mathrm{e}}$ siècle sur le libéralisme", Tolérance et communauté humaine, Tournai, Casterman, 1952, p. 76-103. 
cette condamnation ne reproduit pas l'arsenal développé par les consulteurs dans le secret des délibérations romaines à l'encontre de Lamennais, mais élargit les perspectives et on ne peut comprendre l'encyclique sans tenir compte du contexte qui vint interférer dans son élaboration. En effet, les mouvements libéraux de l'Italie centro-septentrionnale de 1831 s'étaient tournés contre la souveraineté temporelle du Pape et Grégoire XVI en avait appelé à l'Autriche, qui rétablit l'ordre de manière musclée, au printemps 1831 et au début de l'année de 1832. Ce contexte, clairement évoqué au début de l'encyclique et qui introduit à une longue déploration sur l'état de la société contemporaine où l'Église apparaît comme une citadelle assiégée, n'était pas propice à la réception du vœu mennaisien d'alliance de l'Église avec les mouvements «populaires». Les pressions diplomatiques ${ }^{14}$, de la France (présente à Ancône, cité pontificale, à partir de février 1832), de la Russie et surtout de l'Autriche - toutes trois disposées à appuyer Rome dans la reprise en main de son pouvoir temporel ont joué en faveur de la condamnation. Il existait donc des raisons d'alliance objective entre Rome et les puissances, comme le prouvent les consultations des experts qui rejettent spécialement le principe défendu par L'Avenir "d'amissibilité » du pouvoir, à savoir le droit des peuples à sa révocation. Il est clair que, vue de Rome, la Révolution de Juillet était un retour de la furia francese, menaçant de nouveau de contaminer l'Europe, et que le journal de Lamennais participait de cette agitation des esprits. Sous ce point de vue, l'encyclique, rédigée avec peu de recul sur les événements, est circonstancielle et politique, et, quoique motivée aussi par la «question romaine », très différente à cet égard de Quanta cura et du Syllabus de 1864 médités dès 1849 et qui parachevèrent le tournant intransigeant.

Cette configuration explique que Mirari vos resta à un degré de généralité qui n'impliquait pas seulement L'Avenir, pas plus cité que Lamennais. Le pape prit toutefois soin d'écarter toute ambiguïté en confiant au cardinal Pacca, la rédaction d'une note confidentielle à l'attention de Lamennais. Elle lui fut remise le 30 août avec un exemplaire de l'encyclique et spécifiait que les

14. Ibid.; Jean-René Derré, Metternich et Lamennais : d'après les documents conservés aux Archives de Vienne, Paris, Presses universitaires de France, 1963. 
erreurs signalées dans l'encyclique étaient bien aussi celles de L'Avenir. En condamnant les libertés, toutes mises au service des contestations révolutionnaires, l'encyclique prêchait avant tout le devoir d'obéissance des catholiques aux souverains temporels. Il a souvent été affirmé que l'absence de mention de Lamennais dans le texte de l'encyclique était le signe de la charité du Souverain pontife envers un prêtre qui avait rendu de grands services à l'Église, comme d'ailleurs l'avaient rappelé en ces termes les consulteurs. Il y avait aussi des raisons tactiques. Pour la génération aux commandes à Rome, le retour de la révolution réveillait spontanément le spectre du schisme, que l'abbé Chatel avait d'ailleurs, dès 1830, concouru à confirmer en créant l'Église catholique française ${ }^{15}$. Or, l'influence de Lamennais était d'une autre trempe et ne pouvait qu'inquiéter au plus haut degré, d'autant que Rome était circonvenue par des informateurs assez malveillants. La Curie recevait, notamment de la part de l'archevêque de Toulouse et de l'internonce à Paris, des informations alarmantes sur les dissensions que Lamennais faisait régner depuis des années au sein du clergé : spécialement, on l'accusait de soulever le jeune clergé contre l'épiscopat ${ }^{16}$. Lamennais lui-même était convaincu en 1832 qu'on était à l'orée d'un schisme, mais en raison de la politique ecclésiastique du gouvernement de Juillet : celui-ci tenait à maîtriser les promotions à l'épiscopat, et provoquait de vives tensions à l'occasion de ses premières nominations. Ces tensions servaient L'Avenir qui réclamait la séparation de l'Église et de l'État, proposition fermement condamnée par l'encyclique. On comprend mieux sous cet angle la place centrale qu'y tient le rappel à la discipline et à l'obéissance. D'une part, il s'agissait de faciliter les relations diplomatiques avec la France en désamorçant la véhémente opposition entretenue par L'Avenir. D'autre part, l'abstention dans les affaires politiques, imposée de fait par la condamnation des libertés, avait aussi pour but de faire taire les dissensions au sein du clergé français. En ces temps de révolutions, il convenait de

15. Iorwerth Prothero, Religion and clericalism in July Monarchy France. The French Catholic Church of the Abbé Chatel, Lewinston-Queenston-Lampeter, The Edwin Mellen Press, 2005.

16. Garibaldi au Secrétaire d'État du Vatican, 16 novembre 1831 ; lettre de Mgr d'Astros, 29 février 1832. 
resserrer les rangs et d'éviter tout ferment de division. Ce rappel à l'unité nécessaire, dont le moyen était l'obéissance hiérarchique, est le point le plus longuement développé dans le texte pontifical. L'encyclique est donc d'ordre politique et disciplinaire, et se veut pragmatique.

L'attitude passablement dilatoire en ce qui concerne la philosophie mennaisienne, omniprésente pourtant dans les délibérations préparatoires, s'explique mieux : ce n'était pas l'enjeu et il fut décidé de contourner la question. C'est pourquoi les consulteurs proposèrent la voie de l'encyclique : il s'agirait du premier texte du pontificat, rappelant les traditions de l'Église, qui permettrait de ne pas personnaliser les condamnations. Ce n'était pas le système mennaisien qui était l'urgence à traiter, mais plutôt le désordre qu'il jetait. Rome se tint à cette ligne : on répondit ensuite à Mgr d'Astros qu'on ne se prononcerait pas sur sa censure et que l'encyclique suffisait à fixer l'attitude pour le clergé français. Il est assez piquant de noter que le bref à l'archevêque de Toulouse de mai 1833 invitait les évêques à se tourner vers Rome: «redoublez, mettez en commun vos vœux, vos conseils, vos soins, Vénérables frères », spécifiait le bref. C'était une victoire pour Lamennais : les divisions du clergé de France provoquaient l'establishment gallican à obséder le pape qui en profitait pour tenter de prendre la main. D'ailleurs, le rapport de Mgr Frezza exprimait des réserves à l'encontre du parti anti-mennaisien qu'il jugeait peu charitable, tout comme l'internonce à Paris qui refusa, lors des tractations pour obtenir, en novembre-décembre 1833, la soumission inconditionnelle de Lamennais, de laisser carte blanche à Mgr de Quélen, archevêque de Paris : les deux prélats romains décelaient un « esprit de parti », c'est-à-dire des tendances gallicanes. La suspension des activités mennaisiennes, effective en septembre 1832, permettait donc d'éviter de mettre sur la place publique des débats qu'il n'était pas temps de trancher. Cela suffisait bien à cette heure, et le soulagement de l'internonce à Paris après la soumission sans condition de Lamennais de décembre 1833 l'exprime sans ambages: «Bien que je sois persuadé de sa bonne foi, et de la sincérité de ses sentiments, pourtant au fond je ne crois pas que l'Abbé de La Mennais ait modifié ses opinions ; mais en substance il a fait ce que le SaintPère lui a demandé, et c'est cela qui était essentiel pour le bien 
de la paix $»^{17}$. Les autorités romaines s'efforcèrent de maintenir la paix en faisant taire l'opposition à Lamennais, essayant ainsi, et en vain, de dissuader le sulpicien Boyer de publier sa somme contre la philosophie mennaisienne ${ }^{18}$.

Plus surprenant, au regard des délibérations, est la tactique d'amalgame qui fut adoptée. En effet, les «libertés nécessaires » sont condamnées au milieu d'autres erreurs sans rapport avec les thèses de L'Avenir: le mariage des prêtres, la réforme de l'Église (les deux, en référence à l'abbé Chatel, sans doute) et l'indissolubilité du sacrement de mariage. C'était un moyen de diluer la condamnation de Lamennais et le paragraphe qui fait de l'indifférentisme la matrice des maux contemporains ne manque pas de sel si on considère que Lamennais dut sa notoriété au premier volume de l'Essai sur l'indifférence (1817). D'un point de vue doctrinal, Rome optait donc pour la prudence. Tous les consulteurs avaient repoussé un examen approfondi des doctrines mennaisiennes : ils redoutaient la capacité d'argutie d'un esprit subtil et sa dialectique redoutable. Ils déclaraient qu'un tel examen réclamerait une procédure longue, sous-entendant finalement que le système mennaisien posait des problèmes doctrinaux épineux. Rome ne souhaitait donc pas se prononcer, malgré les pressions du P. Rozaven, l'assistant de la Compagnie de Jésus pour la France, qui faisait découler toutes les erreurs de L'Avenir de la théorie du sens commun, pilier de la pensée de Lamennais. Il fut donc décidé de ménager la philosophie mennaisienne en évitant les noms - et, de là, un référencement des propositions erronées.

Ce fut la première fois que la préparation d'une encyclique et ses implications furent à ce point médiatisées. Les jésuites et, assez paradoxalement, les réseaux gallicans (sulpiciens, Frayssinous, Dupanloup qui avaient l'oreille de Mgr de Rohan, archevêque de Besançon et cardinal qui séjournait à Rome après la révolution de Juillet) faisant pression sur le Saint-Siège, envoyèrent en 1832-1833 des informations à L'Ami de la religion qui maintenait en France la suspicion sur les mennaisiens dans l'ordre de l'obéissance. Après l'encyclique, le journal entretint plutôt l'attention sur la question

17. Garibaldi à Mgr Polidor, 20 janvier 1834.

18. Pierre-Denis Boyer, Examen de la doctrine de M. de La Mennais, considéré sous le triple rapport de la philosophie, de la théologie et de la politique, avec une dissertation sur Descartes, Paris, A. Le Clère, 1834. 
de l'orthodoxie de la philosophie de Lamennais en se revendiquant des condamnations de Mirari vos. Il est révélateur que la presse non confessionnelle ne se mêla guère de cette querelle : il s'agissait d'une affaire intra-ecclésiale.

L'obstination et l'évolution de Lamennais vinrent finalement donner raison à ses détracteurs et Singulari nos condamna clairement cette fois l'auteur des Paroles d'un croyant: il était assimilé aux hérétiques et sa philosophie était accusée de remettre en cause l'autorité du magistère. Sans être mentionnée, c'est la doctrine du sens commun qui était visée, de manière toutefois assez lapidaire. Gerbet, le plus actif contributeur à la pensée du Maître, y vit clair : il fit une soumission sans condition à l'encyclique, publiée dans tous les journaux religieux, en mentionnant qu'elle désavouait « un système que j'ai soutenu dans quelques-uns de mes écrits ». La doctrine du sens commun faisait partie de l'arsenal apologétique du XVIII ${ }^{\mathrm{e}}$ siècle (sur la base du canon de saint Vincent de Lérins et de l'œuvre de Bergier, que Lamennais connaissait bien), et il était aussi en vigueur dans la philosophie écossaise qui avait pénétré en France depuis la Restauration, via Royer-Collard et Victor Cousin. Cette ambivalence rendait le sens commun très efficace pour la polémique mennaisienne contre l'indifférence, car il était à la fois en prise avec la tradition et avec le mouvement contemporain des idées. Il prit toutefois chez Lamennais un caractère exclusif, puisqu'il fondait sur cette doctrine le criterium de certitude, donc d'autorité, qui le conduisait, suivant les termes de l'encyclique, à « chercher la vérité hors de l'Église catholique ». Cette encyclique était à la fois politique (rejet des citations évangéliques au service de la révolution) et disciplinaire (Lamennais était « relaps »), mais touchait au cœur de l'apologétique mennaisienne : à moyen terme, cette condamnation fut sans doute la plus importante. En effet, les ménagements de Mirari vos avaient brisé la polémique catholique dans le domaine politique et ecclésiologique, mais ils laissaient en débat ce qui formait la base du système mennaisien : l'anticartésianisme et le criterium de certitude.

\section{b. L'attitude des mennaisiens}

La suspicion entretenue par une partie du clergé motiva en bonne partie les pressions romaines pour obtenir de Lamennais une 
soumission inconditionnelle, c'est-à-dire la déclaration formelle de s'en tenir à «la doctrine exposée dans la lettre Encyclique [...], et à ne rien écrire ni approuver qui lui soit contraire ", qu'il finit laborieusement par accepter en décembre 1833. Était-ce à tort? Ce n'est pas sûr. Il est toutefois plus révélateur de tourner le regard du côté des disciples, plutôt que du côté de l'évolution «psychologique » de Lamennais.

Mirari vos déclencha une vague de soumissions des anciens zélateurs de L'Avenir et de l'Agence générale pour la défense de la liberté religieuse qui appuyait son action: les journaux locaux, relayés par L'Ami de la religion, en publièrent un certain nombre. Il est toutefois difficile d'estimer ce mouvement, la plupart des évêques ayant préféré que ces soumissions restassent dans le secret des relations ecclésiastiques. Dans le cercle rapproché, l'encyclique ne causa aucune défection, si on excepte celle de Lacordaire ${ }^{19}$ mais qui n'était déjà plus mennaisien et dont le reniement public ${ }^{20}$ fut jugé sévèrement par tous ses anciens condisciples. Ceux-là optaient pour la tactique du dos rond : travailler en silence à approfondir la réflexion et repousser à quelques années la reprise de l'activité publique. En septembre 1833, avec Gerbet et Eugène Boré, il était question d'une revue, qui serait fondée dans deux ans, quand les esprits seraient calmés, ainsi que de la fondation d'une maison pour jeunes gens et la publication d'ouvrages non théologiques ${ }^{21}$. Gerbet invita même en juillet 1833 Lamennais à publier, sinon le premier tome de la somme philosophique à laquelle il travaillait encore avec le Maître, du moins un résumé, afin de faire pièce à l'ouvrage que préparait l'abbé Bautain qui malmenait la doctrine du sens commun ${ }^{22}$.

19. Anne Philibert, Lacordaire et Lamennais : la route de la Chênaie, 18221832, Paris, Cerf, 2009.

20. Un article dans L'Univers du 2 mai 1834, où il annonce que l'« École n'existe plus » et les Considérations sur le système philosophique de M. de La Mennais, Paris, 1834.

21. Louis Le Guillou (éd.), Lamennais. Correspondance générale, Paris, Colin, 1971-1981 [CG], t. V, Gerbet à Lamennais, 2 septembre 1833 et Lamennais à Boré, 14 septembre 1833.

22. CG, t. V, Gerbet à Lamennais, 17 juillet 1833. Louis Bautain, De l'enseignement de la philosophie en France au dix-neuvième siècle, Strasbourg, Février, 1833. Paul Poupard, Un essai de philosophie chrétienne au XIX siècle. L'abbé Louis Bautain, Paris, Desclée, 1961. Plus généralement : Louis Foucher, La philosophie catholique en France au XIX siècle avant la renaissance thomiste et dans son rapport avec elle (1800-1880), Paris, J. Vrin, 1955. 
En bref, le projet de « science catholique $»^{23}$, élément clé du dispositif mennaisien, restait à l'ordre du jour, en attendant mieux.

Les mennaisiens ne se privaient pas d'exprimer des réserves sur l'encyclique. Avec sa franchise ordinaire, Montalembert le signifiait dans sa correspondance: «sans adopter aucune des opinions exprimées dans cet acte, le plus funeste des annales de l'Église, nous rentrons dans le silence, reconnaissant que ce n'est pas à nous qu'il appartient de sauver ce que le Pape et les évêques veulent perdre $»^{24}$. Mathurin Houet, responsable du cours d'histoire à Saint-Méen, séminaire mennaisien, et futur supérieur de l'Oratoire de Rennes, émettait aussi des restrictions dans la soumission à son évêque en considérant que «certaines personnes donnent à différents paragraphes de l'encyclique une portée qu'ils ne me paraissent pas avoir $\gg^{25}$. Edmond de Cazalès, sous le couvert de l'anonymat, publiait un long article qui invitait à la soumission, mais signalait que les doctrines de L'Avenir n'étaient pas condamnées, mais seulement désapprouvées ${ }^{26}$. Jean-Marie de La Mennais tâchait de cerner le périmètre réel de l'encyclique et en nuançait la portée : la liberté de la presse était condamnée comme principe, mais pas comme une nécessité du temps ; la liberté de conscience était un fait dans la société présente, mais pas un idéal ; la séparation de l'Église et de l'État était certes blâmée, mais comme débat livré en public ${ }^{27}$. Schématiquement, on distinguait la thèse de l'hypothèse. Comme Lamennais, les disciples voyaient dans la soumission toujours plus inconditionnelle qu'on lui demandait, la persécution des adversaires historiques du mennaisianisme qui abusaient de l'encyclique.

23. François Laplanche, en priorité l'article fondateur : «La notion de science catholique : ses origines au début du $\mathrm{XIX}^{\mathrm{e}}$ siècle », Revue d'histoire de l'Église de France, t. 74, 1988, p. 63-90. Pour une mise en perspective: Claude Langlois, " "La science catholique" et l'histoire de l'exégèse contemporaine ", Archives de sciences sociales des religions, 167, 2014, p. 213-228.

24. Lettre du 14 septembre 1832, Marie-Joseph Le Guillou et Louis Le Guillou (éd.), La condamnation..., p. 261. Lettre transmise à Rome par les bons soins de la police de Metternich.

25. Alfred Roussel, Lamennais d'après des documents inédits, Rennes, H. Caillière, 1892, t. 2, p. 61-62.

26. Revue européenne, 15 novembre 1832.

27. Mémoire présenté lors de la retraite à Saint-Méen d'août ou septembre 1832, Louis Le Guillou, L'évolution de la pensée religieuse de Félicité Lamennais, Paris, Colin, 1966, p. 166-167. 
La parution des Paroles d'un croyant ne modifia pas immédiatement l'état des esprits, à l'exception majeure de Gerbet qui rompit avec le Maître, mais de manière encore non publique. Jusqu'à la veille de Singulari nos, Lamennais trouva des zélateurs: encore en juin 1834, Rohrbacher se proposait de défendre publiquement l'opuscule ${ }^{28}$, tandis que le baron d'Eckstein s'en prenait violemment aux attaques de Lacordaire ${ }^{29}$. Toujours en juin 1834, Combalot réservait l'avenir: "votre livre sera la démonstration sociale la plus belle, la plus complète du catholicisme, et l'avenir vous dédommagera, peut-être, des tribulations du moment $»^{30}$. Il est vrai toutefois que la plupart des disciples avaient déconseillé la publication des Paroles, mais moins en raison de leur contenu - même si la plupart déploraient certaines pages violentes qu'en raison de l'inopportunité de cette publication, susceptible de relancer la suspicion et de fragiliser la reprise de l'activité. Parmi les plus jeunes disciples, c'était l'enthousiasme qui dominait, à l'instar de l'abbé Sibour, futur archevêque de Paris, qui considérait que les Paroles portaient une nouvelle démonstration du christianisme, irréprochable dans l'ordre doctrinal et balayant l'apologétique usée $^{31}$. C'est la publication de Singulari nos qui marqua véritablement la fin du mennaisianisme, encore que la rupture ne fut pas toujours totale. Le cas de l'abbé d'Alzon est révélateur: quoique reconnaissant les excès de Lamennais, il continuait dans sa correspondance à défendre sa philosophie, d'accord en cela, écrivait-il, avec certains prélats romains ${ }^{32}$.

Ce n'est pas le lieu de s'interroger sur ce que les disciples savaient ou acceptaient de l'évolution personnelle de Lamennais, même si l'inquiétude allait croissant à cet égard. Plus important est le fait que la "grande perversité ${ }^{33}$ du volume ne s'imposait

28. CG, t. VI, Rohrbacher à Lamennais, 13 juin 1834.

29. La France catholique, 16 juin et 28 juin 1834.

30. CG, t. VI, de Combalot à Lamennais, $1^{\text {er juin }} 1834$.

31. Ibid., de Sibour à Lamennais, 22 juin 1834. Voir aussi les lettres adressées à Lamennais par Eugène Boré, Breil de Marzan, Maurice de Guérin, d'Alzon, Mac Carthy, de l'abbé Daubrée ou la correspondance de Maurice de Guérin...

32. CG, t. VI, notamment p. 314-320. Voir aussi les contributions de Gaston Bordet, «Emmanuel d'Alzon et la crise mennaisienne » et de Jean-René Derré, «Les relations entre Emmanuel d'Alzon et Lamennais », dans : Emmanuel d'Alzon dans la société et l'Église du XIX siècle, Paris, Le Centurion, 1982.

33. Expression célèbre de l'encyclique de 1834 à l'égard des Paroles, et utilisée à l'identique dans Mirari vos pour condamner la liberté de la presse. 
pas à l'évidence de catholiques zélés. C'est ce qu'il convient d'expliquer: pour ce faire, il faut préciser les objectifs et la réception des Paroles d'un croyant.

\section{Les Paroles d'un Croyant, « EZÉCHIEL déGUISÉ EN JACOBIN » ${ }^{34}$}

Les formes choisies par Lamennais ont rendu souvent trouble le fond de l'ouvrage : les Paroles font alterner, sous le prétexte de songes, des visions terribles et apocalyptiques (la condition actuelle de l'humanité ; les combats qui se préparent ; la conjuration des princes de ce monde) avec des visions de béatitude (l'humanité originelle ; l'humanité délivrée). S'intercalent des paraboles plus sereines qui tendent à atténuer la souffrance du peuple en ayant recours à l'apologétique assez classique de la foi et de l'espérance. Empreint d'un prophétisme fiévreux, l'ouvrage projetait l'horizon d'une cité terrestre fraternelle sous les auspices de la «loi du Christ», atteint au terme de combats dont les peuples sortiraient victorieux.

Les Paroles étaient destinées au peuple, comme Lamennais ne cesse de le dire dans sa correspondance et comme l'atteste la préface rajoutée dans l'édition d'octobre 1835. Cette destination justifiait les formes de l'ouvrage : optant pour la parabole, décalquant les Psaumes, les Évangiles, l'Apocalypse ${ }^{35}$, il visait à réveiller la culture chrétienne «native » que le peuple aurait conservée. En effet, suivant la conception mennaisienne, le peuple, à peu près indemne de la corruption qui travaillait les élites depuis le $\mathrm{XVI}^{\mathrm{e}}$ siècle, portait par essence la charge de la Révélation du Christ puisque c'est elle qui l'avait constitué par l'affranchissement de l'esclavage et par la proclamation de l'égalité de tous devant le Père. Plus ou moins consciemment, le peuple devait donc réaliser la promesse temporelle de la Révélation, à savoir l'application sociale du message de fraternité. Depuis 1827, et le « Mémoire à Léon XII » où cette mythification du peuple apparaît pour la première fois, Lamennais n'avait cessé de se convaincre que le peuple

34. Journal des débats, 24 mai 1834.

35. Yves le Hir, Les Paroles d'un croyant de Lamennais, Paris, Colin, 1949. 
était le moteur de l'histoire. Les Paroles mettaient ces conceptions en œuvre : le merveilleux chrétien était le langage adapté pour un peuple qui en connaissait la grammaire ; le témoignage du Croyant était la forme d'enseignement appropriée ; le poète au ton prophétique évitait les démonstrations inaccessibles. Lamennais écrivait lui-même des Paroles : « il faut pousser les hommes à l'action par les pensées qu'ils comprennent et par les sentiments qui les remuent $»^{36}$.

Il n'échappait pas à des disciples familiers de la doctrine que les Paroles n'étaient rien d'autre qu'une poétisation de la philosophie mennaisienne, conservant dans ses soubassements les deux piliers de cette philosophie. La doctrine du sens commun d'abord: dans l'assentiment du nombre, réside le criterium de certitude, et la masse conserve le dépôt de la foi, sous une forme non dogmatique ; c'est pourquoi l'avenir appartient aux peuples. La distinction entre ordre de foi et ordre de conception ensuite : l'homme admet d'abord pour vrai ce qu'il croit d'autorité, antérieurement à tout exercice de la raison qui ne peut se déployer dès lors que dans ce cadre ; c'est la fonction dévolue au Croyant, qui parle d'autorité. Les Paroles relèvent bien de l'anthropologie mennaisienne, enfouie dans les fondements d'un ouvrage composé sans raisonnement suivi - selon les mots de l'auteur. Malgré les réticences à l'égard des attaques outrancières contre les princes, l'utopie mennaisienne d'une régénération politique et sociale par l'esprit agissant de l'Évangile tenait encore bon chez les disciples. Par ailleurs, en 1833, au moment de la rédaction des Paroles, Lamennais était encore catholique et, comme le souligne l'abbé Duine, les Paroles conservent « un caractère assurément confessionnel $»^{37}$. L'ouvrage se situe en fait sur une ligne de fracture, non seulement celle de l'évolution personnelle de son auteur, mais celle qui courait depuis le séisme de 1830 et interrogeait sous toutes ses coutures le statut de la religion en France et dans une Europe en ébullition. Sous ce point de vue, Lamennais prenait déjà d'un peu haut ce

36. CG, t. VI, Lamennais à $\mathrm{M}^{\mathrm{me}}$ de Vaux, juin 1834.

37. François Duine, La Mennais : sa vie, ses idées, ses ouvrages, d'après les sources imprimées et les documents inédits, Paris, Garnier frères, 1922, p. 199. C'est à peu près l'avis d'Henri de Lubac, qui considère toutefois que Lamennais n'était plus lors de la sortie des Paroles dans le même état d'esprit « d'orthodoxie » qu'au moment de leur rédaction (La postérité spirituelle..., p. 439-460). 
qui inquiétait ses disciples : «les questions sur lesquelles on me chicane sont enveloppées dans tout autres questions et paraissent si petites dans celles-ci, qu'il n'y a pas lieu de s'en occuper $»^{38}$. Cette pensée, qui est au principe des Paroles, doit être élucidée.

Lamennais considérait que la réception de Mirari vos montrait surtout l'affaiblissement de l'autorité pontificale puisque la presse l'aurait accueillie avec indifférence. Il est vrai que les journaux se limitèrent généralement à publier le texte, en l'agrémentant parfois d'un commentaire, et la Revue des deux mondes n'en fit pas même mention, sinon un peu incidemment ${ }^{39}$. Outre l'adhésion sans réserve des journaux catholiques, deux positions se distinguèrent qui pouvaient justifier l'opinion de Lamennais. La première, celle de la presse du régime, considérait surtout qu'il s'agissait d'une affaire entre prêtres, et se limitait, tout au plus, à dénoncer les empiétements de «l'ultramontanisme» sur les libertés civiles, ranimant les débats ouverts sous la Restauration, en 1825-1826 ${ }^{40}$, en appelant au secours les articles de 1682 et le gallicanisme « parlementaire $»^{41}$ : ce débat n'avait plus sérieusement cours alors que depuis 1830 le catholicisme n'était plus religion d'État. Plus significative était la seconde position, celle des républicains, et spécialement des héritiers divisés du saint-simonisme. L'Européen prenait résolument la défense de L'Avenir en intentant un procès à la papauté qui venait de « traîner la croix de Jésus dans la boue $»^{42}$ : c'est au nom même des principes chrétiens qu'étaient défendues les libertés condamnées par Rome. La Revue encyclopédique saluait, non sans ironie, la grandeur d'un acte qui réveillait la tradition d'une institution « qui oublie un instant sa vieillesse et sa décrépitude » et se levait de son lit d'agonie car on lui demandait de «pactiser avec le monde moderne »-formule heureuse qui ne donnera toute sa mesure qu'à l'heure des polémiques sur le

38. CG, t. V, Lamennais à Mac Carthy, 9 décembre 1832.

39. Eugène Lerminier, "Lettres philosophiques à un Berlinois, VIII », Revue des deux mondes, 1832 , t. 3 , p. 746.

40. Sylvain Milbach, "'Les coups de cette épée dont la poignée est à Rome et les coups partout". 1825-1826 : La Mennais et Montlosier, un tournant antiromain?», Sylvio de Franceschi (dir.), Histoires antiromaines II. Actes de la journée d'études de Munich (13 septembre 2013), Lyon, LARHA, 2014, p. 157-179.

41. Le Constitutionnel, 9 et 13 septembre 1832.

42. L'Européen, 15 septembre et 16 octobre 1832. 
Syllabus : une religion nouvelle s'imposait. Passée sa publication, l'encyclique de 1832 ne provoqua guère de polémiques: les journaux gouvernementaux étaient eux-mêmes pour le moins réservés quant à l'usage illimité des libertés, surtout au service d'un catholicisme combatif ; ceux d'opposition de gauche voyaient dans l'encyclique la preuve que l'Église était sortie de l'Histoire. Mirari vos ne faisait donc, pour Lamennais, que consolider des positions nocives pour l'avenir de la société. C'était un acte nul. En 1834, Singulari nos souleva encore moins de commentaires et, finalement, la plupart des journaux se félicitèrent de la condamnation.

Cette relative atonie contraste avec le succès inouï remporté par les Paroles, le best-seller de la décennie ${ }^{43}$ avec Mes Prisons de Silvio Pellico, autre apologie du sentiment chrétien, il faut le noter, fort bien reçue d'ailleurs par la presse, à la grande différence des Paroles. Lamennais ne s'en étonnait pas: il mettait en scène le « chrétien actif », là où Pellico valorisait le « chrétien passif ». Les journaux ont consacré aux Paroles de très nombreux articles ${ }^{44}$ : catholiques, protestants, gouvernementaux, fouriéristes même, tombaient d'accord pour stigmatiser cet «évangile de la révolte » et anticipaient sur Singulari nos. La presse a pris très au sérieux un ouvrage qui pourtant se distinguait par son caractère fantasmatique et ses exagérations; elle contribua à son succès. Les Paroles donnèrent aussi lieu à une foule de répliques, toutes, ou peu s'en faut, des réfutations qui ne cédaient en rien aux amplifications de l'original, en reprenaient souvent les formes messianiques, donnant l'impression d'une véritable fièvre de visions en cette année 1834 . Franck-Paul Bowman a judicieusement souligné que ces répliques s'apparentaient à des pastiches, mais pas à des parodies ni à des satires ${ }^{45}$. On prenait décidément très au sérieux les visions du Croyant auquel était prêtée une réelle influence et cette inquiétude aux accents de panique mérite explication.

43. Huit éditions pour la seule année 1834, et on peut évaluer à environ 60000 , le nombre d'exemplaires mis sur le marché en France jusqu'en 1840. Il faudrait ajouter à ces tirages, des éditions « pirates » et de nombreuses traductions, d'autant plus difficiles à repérer que l'ouvrage fut interdit en certains États.

44. Sur la réception des Paroles: Paul Vulliaud, Les Paroles d'un croyant de Lamennais, Amiens, Éditions Edgar Malfère, 1928.

45. Franck Bowman, «Les pastiches des Paroles d'un croyant», Actes du colloque Lamennais. Cahiers mennaisiens, 16-17, 1983-1984, p. 144-154. 
Les Paroles furent publiées alors que dans différents secteurs de la société, il était accordé la plus grande attention au rôle social de la religion, réflexion qu'avait finalement inaugurée L'Avenir. La persistance du désordre et de l'opposition politique favorisait ce renouveau car elle entretenait une incertitude qui signifiait que la révolution n'était pas achevée et prenait même, avec les fameux soulèvements des canuts de Lyon, des allures de guerre sociale: l'ordre de Juillet paraissait précaire, sinon transitoire. Les témoignages ne manquent pas pour montrer que le début de l'année 1834 vit, dans l'ordre réel ou hyperbolique, un apogée des inquiétudes et des espoirs qui se concrétisèrent par la répression du gouvernement ${ }^{46}$. Les Paroles passaient pour un brûlot jeté au milieu d'un peuple ouvrier en effervescence. Dans ce contexte, le seuil de sécularisation institutionnelle provoqué par la révision de la Charte - l'abrogation de la religion d'État - déplaçait la question religieuse telle qu'elle avait été débattue sous la Restauration. Elle avait été alors, dans le contexte de l'alliance du trône et de l'autel, une question éminemment politique, et l'anticléricalisme était une arme dans les mains des adversaires du régime. Avec 1830, la question devint sociale parce que les troubles qui persistaient interrogeaient les moyens d'ordre moral qui avaient été communément attribués, depuis l'Empire, au catholicisme. À cet égard, il est révélateur que ce soit à partir de 1834 que le gouvernement ait réorienté sa politique ecclésiastique dans le sens d'un apaisement : en trouvant un modus vivendi dans la procédure de nomination des évêques, en levant l'interdiction des conférences et des retraites ecclésiastiques, en rétablissant les frais d'installation et le traitement des cardinaux, en maintenant finalement les évêchés créés après 1814, etc. Au fond, la révolution ramenait spontanément la question religieuse née en 1790-1791, mais elle prenait une forme bien plus ample dans l'élite, une génération qui avait conçu, contrairement à celle de la Révolution, le catholicisme plus comme un facteur (conflictuel) de la vie politique que comme un encadrement croyant.

Il est clair que dans ce contexte, le succès remporté par les Paroles dans les milieux républicains, et « populaires » pensait-on,

46. On se limitera à renvoyer à deux témoignages : Louis Blanc, Histoire de dix ans, Paris, Pagnerre, 1843, t. 4, p. 189-308 et Charles de Rémusat, Mémoires de ma vie, Paris, Plon, 1960, p. 61-79. 
était inquiétant: les Paroles «valent pour notre cause plus que des milliers de baïonnettes, car elles feront dans les populations des conquêtes morales », écrivait Cabet ${ }^{47}$. Le Journal des Débats, d'ordinaire si posé, accusait Lamennais de mettre « le doigt dans les plaies les plus saignantes: il les envenime, les empoisonne, les élargit $»^{48}$. Les visions des Paroles, morbides, sanglantes, le thème conspirationniste, le ton vengeur de l'ouvrage brassaient toutes les hantises sociales. À l'heure des répressions de Lyon et de Paris en avril 1834 - les Paroles furent mises sur le marché le 30 avril -, du massacre médiatisé de la rue Transnonain, il était difficile d'interpréter les Paroles au second degré. Pourtant, là n'était pas la signification de l'ouvrage, ni pour Lamennais ni sans doute pour la plupart des républicains qui l'accueillirent avec enthousiasme. Les répressions d'avril 1834 leur avaient porté un coup que certains d'entre eux, comme Marrast depuis sa prison considéraient comme fatal, du moins à court terme : «si nous avons pris la plume, ce n'est ni par le besoin de combattre, ni par l'espoir de vaincre », confiait-il ${ }^{49}$. Comme l'écrit ThureauDangin, triomphalement : «partout donc, avortement ou défaite de l'insurrection », l'opposition était «en déroute ${ }^{50}$. C'était l'avis de Lamennais. Suivant sa volonté explicite, les Paroles tombaient comme une consolation. Il apportait à ceux qui se revendiquaient du peuple la caution de la Révélation. Il faisait entrer la mystique en République. Les Paroles semblaient réserver l'avenir et servirent à repousser à plus tard les aspirations de 1830: elles étaient une promesse plus qu'un programme. Edgar Quinet, parmi d'autres, fit part de son enthousiasme à l'auteur des Paroles, alors qu'il ébauchait en 1833 son Génie des religions (1842): «l'avenir écrit dans ces pages nous aidera à mieux supporter le présent $[\ldots]$. Vous avez délié la langue de cette époque qui était muette et vous avez prononcé la parole de vie dans le chaos »; et il ajoutait: " nous sommes dans la mort et nous frappons de la tête

47. Le Populaire, 11 mai 1834 ; Le National, 28 avril 1834 ; la Revue républicaine, t. 1, 1834, p. 202-220 ; la Revue encyclopédique, t. LX, 1833, etc.

48. Journal des débats, 24 mai 1834.

49. Armand Marrast, Vingt jours de secret ou Le complot d'avril, Paris, Guillaumin, 1834, préface.

50. Paul Thureau-Dangin, Histoire de la Monarchie de Juillet, Paris, Plon, 1884-1892, t. 2, p. 249. 
notre tombe pour ressusciter et c'est vous qui nous avez le premier réveillés $\gg^{51}$.

Finalement, Lamennais entretenait les promesses de L'Avenir en proposant une foi active qui allait droit au siècle. Les hantises et les passions que l'ouvrage mettait en scène signalent que, comme en 1817 avec l'Essai sur l'indifférence, il sut en 1834, encore au lendemain d'un changement de régime politique, recharger les attentes religieuses. Il avait aussi une claire conscience que l'indécision des temps présents laissait émerger une configuration politico-religieuse originale et nouvelle qu'il fallait encadrer. Pour comprendre cette opération, il faut en revenir au «génie puissamment assimilatif » que Ballanche prêtait à Lamennais.

\section{3. « LES PLANS DE RELIGION PULLULENT DEPUIS QUELQUES ANNÉES $»^{52}$}

Le début des années 1830 se caractérise par une ébullition croyante et d'amples spéculations d'essence religieuse. Cette configuration mériterait sans doute une étude systématique car elle est formée d'éléments très hétérogènes, mais il est possible de dessiner les contours de débats qui nous ramènent au paradigme mennaisien et à l'inquiétude religieuse qui participa de l' « esprit de $1830 \gg$.

\section{a. De hautes-eaux croyantes}

Dans l'ordre spéculatif, les «hétérodoxies romantiques » connaissaient leur première floraison. Le saint-simonisme façon Bazard et Enfantin, condamné en 1832, en fut la manifestation la plus retentissante, mais la religiosité saint-simonienne était la partie émergée d'un plus vaste iceberg. En 1831, après une extase, Louis Tourreil, un ancien officier de Marine, se persuada qu'il lui échoyait de porter la «nouvelle parole»: il fondait la religion fusionienne. Entre 1831 et 1833, Gustave Drouineau, auteur dramatique qui avait rencontré un beau succès en 1828 avec sa pièce Rienzi, se proclamait le propagateur du «néo-christianisme ».

51. CG, t.VI, Quinet à Lamennais, 22 juin 1834.

52. La Dominicale, t. 2, 1834, p. 328. 
En 1831, Bernard-Raymond Fabré-Palaprat publiait son Levitikon et se déclarait pape des «chrétiens catholiques primitifs ». En 1832-1833, l'ingénieur des Mines Moisson-Desroches, ancien polytechnicien, se lançait dans la théologie et se déclarait adepte du conciliantisme, religion nouvelle. En 1833, Gabriel Galland, ouvrier lyonnais, publiait une «Annonce sans pareille» qu'il fit suivre, en 1834, d'une Loi universelle. Justice naturelle ou divine. Un nommé Amable Bellée publiait en 1834 une Lettre prophétique et apostolique. L'Euvre des enfants de Dieu réunis en familles spirituelles de François-Guillaume Coëssin trouvait une seconde vigueur. Augustin Chaho, auteur d'un des pastiches les plus originaux des Paroles, se piquait aussi de théologie et de cosmogonie : il se déclarait, contre le Croyant, héritier d'une religion primitive transmise par une chaîne de voyants, dont il était le représentant actuel; il prévoyait que les années 1830 préparaient un «Quatrième Âge de l'humanité ». Les revues rendaient compte de ces novations religieuses, sur un mode certes parfois ironique, mais elles en rendaient compte ${ }^{53}$. Ces novations n'avaient pas vraiment d'ambitions politiques, mais avaient la volonté de reconstruire la cohésion sociale autour de valeurs religieuses adaptées à la société nouvelle : c'est au fond ce qui motivait le schisme provoqué par la création de l'Église catholique française de l'abbé Chatel, autre théologie « de l'air du temps » ${ }^{54}$. Le genre prophétique et parabolique allait bon train.

Les questions religieuses étaient par ailleurs à la mode dans les lieux académiques où elles surgissaient en histoire, en philosophie, en droit ou dans les cours de littérature, comme dans ceux d'Ampère qui déclarait du haut de sa chaire du collège de France : «entendez de toutes les bouches, de tous les livres, de toutes les chaires, partir des voix qui appellent ou promettent un renouvellement religieux, moral, social $»^{55}$. La Revue des deux mondes se fit l'écho

53. Citons : «Chronique », Revue des deux mondes, 1833, t. 1, p. 105 et suiv. ; ibid., 1833, t. 2, p. 476-477 ; Eugène Pelletan, «Des religions nouvelles », La nouvelle Minerve, 5,1836, p. 525 et suiv.

54. Philippe Boutry, "Théologie de l'air du temps et ecclésiologie de circonstance: l'abbé Chatel et l'Église catholique française », Patrick Harismendy (dir.), La France des années 1830..., op. cit., p. 85-112.

55. Jean-Jacques Ampère, « De l'histoire de la littérature française. Discours prononcé au Collège de France le 14 février 1834 », Revue des deux mondes, 1834, t. 1, p. 424. 
de ces opinions et traita la question sur un mode élevé et savant, spécialement sous la plume d'Eugène Lerminier, juriste, issu de l'école du Globe libéral, promu, après un court rapprochement avec les saint-simoniens, à la chaire de législations comparées du Collège de France en 1831, à vingt-huit ans ${ }^{56}$. C'est dans cette même revue que fut publié en 1834 l'«Avenir du monde» de Chateaubriand, assez proche des prophéties mennaisiennes ${ }^{57}$. Une autre revue aux couleurs notabiliaires, la France littéraire, jouissant de patronages prestigieux, fit une place plus importante encore à la religion dans l'ordre historique et philosophique ${ }^{58}$. Elle convoqua des auteurs, membres de l'Institut et beaucoup de provinciaux, femmes et hommes, qui exposèrent, presque dans chaque livraison entre 1832 et 1835 , des conceptions religieuses éclectiques, entre spiritualisme chrétien et orthodoxie, explorant toutes les liens entre religion, histoire, philosophie, arts, sciences, morale et avenir de la société. Elle rassembla ainsi des partisans de la « politique sociale » de Lamartine (Angebert ${ }^{59}$ ), des catholiques en rupture de ban (Esquiros ${ }^{60}$ ), d'autres catholiques qui exploraient aux limites de l'orthodoxie (Ballanche et ses disciples lyonnais comme Falconnet ${ }^{61}$ ), des anti-mennaisiens (l'abbé Flottes, l'abbé Bautain $^{62}$ ) ou des disciples de Lamennais (Du Breil de Marzan ${ }^{63}$ ), des collaborateurs de la Revue encyclopédique (Auguste Bouzenot), des professeurs de philosophie de l'Université (Adolphe Mazure,

56. Sur Lerminier: Lerminier. Corpus, revue de philosophie, $\mathrm{n}^{\circ}$ 60, 2011 (sous la direction de Georges Navet).

57. Sylvain Milbach, " "Nous imbéciles, croyants de liberté, nous causons de choses sérieuses". Chateaubriand et Lamennais autour de 1834 : christianisme et avenir », Bulletin de la Société Chateaubriand, $\mathrm{n}^{\circ}$ 57, 2014, p. 91-103.

58. Brian Juden, La France littéraire de Charles Malo et Pierre-Joseph Challamel, Paris, Champion, 1974.

59. Caroline Angebert, «De la religion et de la philosophie dans leur opposition et leur identité », La France littéraire, t. 4, 1832, p. 498-520.

60. Alphonse Esquiros, «Philosophie du christianisme», La France littéraire, t. 19, 1835, p. 5-47.

61. Ballanche publie, notamment, des extraits de sa Ville des expiations. Ernest Falconnet, «Du rationalisme et du mysticisme en France », La France littéraire, t. 4, 1832, p. 87-112.

62. Abbé Flottes, «De la foi sous le rapport philosophique », La France littéraire, t. 13,1834 , p. 5-23; tout comme dans la Revue européenne, l'abbé Bautain publie dans cette revue.

63. François du Breil de Marzan, «Les Paroles d'un croyant », La France littéraire, t. 13, 1834, p. 24-42. 
traducteur de Schlegel), des polygraphes, souvent prolixes ensuite $\left(\right.$ Leclère $^{64}$, Celnart $^{65}$, Roux-Ferrand $\left.{ }^{66}\right)$.

Les catholiques n'étaient pas en reste : plus ou moins dans le sillage de l'œuvre de Lamennais, quoiqu'il les désavouât, les Annales de philosophie chrétienne (1830) et la Revue européenne (1831) tâchaient, chacune en leur domaine, de revitaliser les liens entre la tradition catholique, le sens de l'histoire et les enjeux de la société contemporaine. Des revues destinées à la défense des intérêts religieux furent créées à la suite de la chute de L'Avenir. L'écho de la jeune France, journal des progrès par le christianisme (1833), de tendance légitimiste libérale, se proclamait d'une parfaite orthodoxie. Les Études religieuses (1833) ${ }^{67}$ tenaient à affronter les questions religieuses que soulevaient les grands organes de l'élite censitaire, engageant, comme la Revue européenne, la polémique avec eux, et spécialement avec Lerminier. Ces revues se firent une spécialité du recensement et de la discussion du «mouvement religieux » de l'époque : notamment La Dominicale $(1833)^{68}$, qui se targuait d'avoir l'assentiment de l'archevêque de Paris. Il est impossible d'entrer ici par le menu dans l'analyse de ces revues, mais elles ont des traits communs qu'il convient de souligner. Elles entretinrent un dialogue serein, et optimiste quant à l'avenir, avec les idées du siècle qui se traduisit par une polémique courtoise, quoique ferme ; un ton qu'on ne retrouve pas dans L'Ami de la religion ou dans le jeune journal L'Univers. Les articles concernant l'actualité du catholicisme dans ses liens avec les questionnements philosophiques et historiques tinrent une place centrale dans ces publications qui se fixaient pour but d'encadrer le «mouvement religieux » qui semblait animer la société. Elles s'appuyaient, sans les revendiquer, sur les principes de l'apologétique mennaisienne : le sens commun et la distinction des deux ordres, pour

64. Jean-Baptiste Leclère, «Régénération sociale », La France littéraire, t. 8, $9,10,1833$ et t. 10,1834 .

65. Elizabeth Celnart, « De la morale de l'Évangile comparée à la morale des philosophes », La France littéraire, t. 15, 1834, p. 194-213.

66. Hippolyte Roux-Ferrand, « $\mathrm{Du}$ christianisme, des causes et des conséquences de son établissement en Europe », La France littéraire, t. 4, 1832, p. 288-309.

67. L'abbé Narcisse Cacheux, principal contributeur de la revue semble-t-il, débute une longue carrière de philosophe catholique.

68. On ne possède pas de renseignements sur ce journal, dont les articles ne sont pas signés, sinon qu'il fut dirigé par Ange de Saint-Priest. 
les Études religieuses; la défense des intérêts catholiques par la liberté de la presse, pour La Dominicale. Toutefois, ces revues étaient sans lien direct avec le Maître, et désavouèrent sans réserve les Paroles dès leur parution ${ }^{69}$. La Dominicale tenta toutefois de sauver le système mennaisien de la condamnation portée par Singulari nos ${ }^{70}$. Ce qui importe ici, c'est de rétablir le dialogue qu'ont entretenu ces périodiques afin d'en dégager les enjeux.

\section{b. Le fait croyant, une question sociale}

En premier lieu, la question religieuse y revêtit une dimension civilisationnelle, qui était souvent aussi au fondement des hétérodoxies et des nouvelles religions. Le début de ces années 1830 a été une période de renouvellement dans l'ordre des savoirs qui toucha tant la production savante laïque que le clergé ${ }^{71}$. Sans doute, la Restauration avait vu s'amorcer de nouvelles approches du fait religieux, en réaction au rationalisme des Lumières, qui fournissaient un certain nombre d'arguments : De la Religion de Benjamin Constant (1824) avait analysé le sentiment religieux et, avec le baron d'Eckstein (Le Catholique, 1826-1829), avait importé en France le renouveau de la philosophie et de l'érudition allemandes; le Mémorial catholique de Lamennais (1824-1830) avait développé une apologétique en réponse à ce renouveau. Mais ces débats étaient restés d'ordre philosophique, ou plutôt, dirait-on aujourd'hui, anthropologique ${ }^{72}$. Ce qui changea après 1830 fut l'étroite connexion opérée entre l'actualité, les interrogations religieuses et la «question sociale » qui levait. La condamnation des Lumières par la philosophie traditionaliste gagnait du terrain car l'apparente fragilité du régime de Juillet semblait révéler que le travail de sape sociale du XVIII ${ }^{\mathrm{e}}$ siècle se perpétuait indéfiniment.

69. La Dominicale, t. 1, 1833, p. 571-574 ; Études religieuses, t. 5 et 6, 1834, p. 133-136 et 186-190; L'écho de la Jeune France, t. 2, 1834, p. 69-79.

70. «De l'encyclique », La Dominicale, t. 2, 1834, p. 85-88.

71. Michel Despland, L'émergence des sciences de la religion. La monarchie de Juillet : un moment fondateur, Paris, l'Harmattan, 1999 ; François Laplanche, La Bible en France entre mythe et critique, XVI ${ }^{e}-X I x^{e}$ siècles, Paris, Albin Michel, 1994.

72. Pour un aperçu sur l'esprit des débats de cette période : Sismondi, « Revue des progrès des opinions religieuses », Revue encyclopédique, t. 29, 1826, janvier, p. 21-37 et p. 349-365. 
L'influence de l'œuvre de Bonald ne doit pas être mésestimée, ainsi que celle de Joseph de Maistre que toute cette génération avait lu, sans en adopter évidemment toutes les conclusions ${ }^{73}$. Le rationalisme était intimement lié à la «question sociale » car lui étaient annexés le matérialisme et l'individualisme, levain dissolvant de l'ordre, qu'incarnait d'ailleurs le gouvernement de Juillet aux yeux de ses adversaires. Il s'agissait en priorité de comprendre le sens de la révolution de 1830, que venait hanter en permanence le spectre de la grande Révolution et de 1793. Cette interférence révélait des hantises face à l'ombre portée d'une Révolution qui n'appartenait pas à l'histoire: ce n'était pas un événement clos. La société en France se distinguait par une inquiétante pluralité d'opinions et d'intérêts qui paraissait le symptôme d'une pathologie sociale, et l'état de l'Europe, agitée par le sentiment de nationalité, semblait confirmer qu'on se trouvait dans une période de transition civilisationnelle dont on ne voyait pas l'issue.

Parmi les «prophètes » se multipliant, Ballanche était un auteur fort révéré, davantage lu alors que Saint-Simon, omniprésent dans la presse de l'époque: sa philosophie de l'histoire, et son interprétation "palingénésique », qui n'était pas sans parenté avec celle des saint-simoniens et d'autres « prophètes », et sa conception tragique des cycles de destruction semblaient se conjuguer au présent $^{74}$. La révolution qui ne finissait pas prouvait que la société était «en travail»d'un nouvel état - «nous sommes dans une entr'acte du grand drame social qui a commencé en 1789 », disait Ampère dans la conférence déjà citée ; la métaphore de la chrysalide était à la mode; l'avenir suscitait des espoirs mâtinés d'inquiétudes. Les diverses opinions partageaient un horizon commun : rétablir une société du consensus qui ne semblait pouvoir découler que de l'unanimité de croyance, garantie d'obéissance pour les uns, d'harmonie - un mot en vogue - pour les autres et, en tous les cas, de paix sociale. L'ordre matériel semblait dépendre d'un magistère spirituel. Théodore Jouffroy, philosophe éminent alors, considérait le scepticisme contemporain comme conjoncturel

73. Carolina Armenteros, L'Idée française de l'histoire. Joseph de Maistre et sa postérité (1794-1854), Paris, Garnier, 2013.

74. Arthur Mac Calla, A romantic Historiography : The Philosophy of History of Pierre-Simon Ballanche, Leiden, Brill, 1998. 
et temporaire. Il l'expliquait par le fait qu'il y avait «dans le tems $[\mathrm{sic}]$ présent une absence de criterium en matière de vrai et de faux $\gg^{75}$. Le scepticisme était un leitmotiv dans les articles des revues, le mal du siècle qui interdisait la fonction de tout magistère spirituel. Sur ce point l'accord était assez général dans les élites, et les revues catholiques partageaient ce constat.

L'accord n'était pas moins général sur les motifs d'espoir. La révolution de Juillet aurait été marquée par une rupture générationnelle, incarnée d'ailleurs par la victoire du romantisme qui, pour ne pas faire l'unanimité, signalait que la jeunesse avait rompu avec l'héritage des Lumières: le scepticisme était considéré comme une sortie de l'ère des Lumières, une phase de décompression. La Dominicale déclarait qu'à l'encontre de la foi, « le doute a remplacé la haine ; c'est un progrès immense $»^{76}$. Les revues catholiques saluaient le mouvement des idées, cette « réaction religieuse qui s'opère de toutes parts $»^{77}$ et voyaient « toutes les questions politiques agrandies de toute l'immensité des vérités religieuses ${ }^{78}$. Sans doute, les esprits ne revenaient pas en voie directe au catholicisme, mais ils cherchaient «quelque chose qui soit plus durable que ce monde; et qui nous repose et nous en console $»^{79}$. L'écho de la jeune France se fixait pour programme de «régulariser cette tendance chrétienne » qui animait la jeunesse ${ }^{80}$. En tout état de cause, la critique des adversaires spiritualistes était ferme, mais polie et respectueuse ${ }^{81}$. La Revue des deux mondes signalait aussi la vitalité multiforme de la littérature et des travaux touchant la religion ${ }^{82}$. La France littéraire, faisait le

75. «Sur le scepticisme de notre époque, leçon du 24 mars 1834 », Théodore Jouffroy, Cours de droit naturel, Paris, 1834, p. 14.

76. « Du scepticisme au XIX ${ }^{\mathrm{e}}$ siècle », La Dominicale, t. 3, 1835, p. 89.

77. Revue européenne, t. 1, ns, 1835, p. 106.

78. «Le gouvernement philosophique et le gouvernement religieux », La Dominicale, t. 1, 1833, p. 492-496, 593-596, 665-667.

79. «Du mouvement religieux et des devoirs que la situation actuelle impose aux catholiques », La Dominicale, 1834, t. 2, p. 325-331, 345-348, 365-368, 385-389, 445-449, 508-512.

80. L'Écho de la jeune France, t. 1, 1833, p. 317.

81. Par exemple: "Mélanges philosophiques de Jouffroy», Revue européenne, t. 7, 1833, p. 98-115; "Résignée, par Gustave Drouineau », ibid., t. 4, 1832, p. 470-484.

82. «Tendance des esprits vers la religion», Études religieuses, t. 3, 1833, p. 77-81 ; Eugène Lerminier, "Débats sur le christianisme», Revue des deux mondes, 1835 , t. 3, p. 229-242 ; «Du mouvement de la presse en 1835 », 
même constat. Un long article consacré au sentiment religieux prévoyait l'ouverture proche d'une rénovation spirituelle qui coïnciderait avec la fraternité définitive de tous les peuples; le XIX ${ }^{\mathrm{e}}$ siècle se caractérisait par le cri «j'ai besoin de croire en Dieu » - formule utilisée à l'identique par La Dominicale ; "pour qu'un nouveau progrès s'accomplisse, il faut attendre l'avènement de la loi du Christ, la promulgation de la morale évangélique ${ }^{83}$. Toute l'élite convergeait pour considérer qu'il n'y avait pas de société possible sans religion et que la foi était un besoin naturel de l'homme. À ce titre, les catholiques allaient jusqu'à saluer, en exerçant un tri scrupuleux il est vrai, l'œuvre de Victor Cousin, promu philosophe officiel du régime ${ }^{84}$ : l'éclectisme en voie de triompher dans l'Université faisait la part aux besoins spirituels de l'humanité. Néanmoins, les catholiques comme les penseurs radicaux, Lamennais appartenait alors aux uns et aux autres, y voyaient aussi un bricolage transitoire qui faisait son marché dans les systèmes philosophiques, mais n'aboutissait qu'à une synthèse contradictoire qui confirmait le désarroi du temps : cette philosophie ressemblait fort à la transaction du régime de Juillet et à la marqueterie sociale de la société contemporaine.

Pour autant, ce sentiment religieux était assez vague et prenait des formes variées. Le périmètre d'action de la raison était au cœur du débat: si le rationalisme du XVIII ${ }^{\mathrm{e}}$ siècle était battu en brèche de tout côté, il restait du moins à réagencer les relations entre raison et foi. Les spéculations, sur fond de philosophie de l'histoire, se concentraient sur les attributions respectives de la philosophie et des vérités de religion, et de leur articulation avec le progrès. Les savoirs nouveaux commençaient à peine à bouleverser les rapports à la tradition chrétienne et on se refusait généralement à y voir une contradiction irréductible. Recouvert par le positivisme de la fin du siècle, ce commerce entre religion

Revue des deux mondes, 1836, t. 2, p. 69-74 ; «Du mouvement religieux...», La Dominicale; voir aussi les comptes rendus bibliographiques de la Revue européenne.

83. Charles Villagre, «Du sentiment religieux », La France littéraire, t. 18, 1835 , p. $5-23$

84. Patrice Vermeren, Victor Cousin, le jeu de la philosophie et l'État, Paris, L'Harmattan, 1995 ; Jérôme Grondeux, «Raison, politique et religion au XIX $^{\mathrm{e}}$ siècle : le projet de Victor Cousin, dossier de publications (1994-2008)», mémoire d'habilitation à diriger des recherches, Paris IV - Sorbonne, 2008. 
et science avait même été encouragé par l'essor des connaissances nouvelles depuis la fin du $\mathrm{XVIII}^{\mathrm{e}}$ siècle $^{85}$. Le décryptage des « hiéroglyphes de la nature ${ }^{86}$ pouvait se mettre au service de toutes les causes, de tous les systèmes, de toutes les élucubrations. Toutes les revues ne cessaient de rappeler le rôle civilisateur du christianisme qui donnait lieu à de longs développements. La Revue des deux mondes déclarait que "depuis le christianisme, il n'y a rien de vraiment grand et beau sur la terre que d'être un homme $»^{87}$. Conformément à l'historiographie libérale, le rôle de l'Église catholique était aussi souvent reconnu, du moins jusqu'au $\mathrm{XVI}^{\mathrm{e}}$ siècle dont, là encore mais pour des raisons différentes, tous les partis reconnaissaient qu'il faisait rupture. On spéculait plus encore sur l'Antiquité tardive, obsédante période de changement de civilisation: le succès du christianisme constituait une étape indiscutable du progrès humain. Toutefois, là commençaient les dissentiments : quelle était la nature de ce progrès et quel rôle y jouait la providence ? Exemplaire à cet égard, la polémique sur la victoire naturelle ou surnaturelle du christianisme sur le paganisme ${ }^{88}$. Pour partie par transposition des débats scientifiques, la civilisation était assimilée à la vie de l'être : elle se développait et mûrissait dans l'histoire. Cette idée introduisait à ce qu'on pourrait nommer un transformisme des vérités de foi et posait de fait la question de la nature de la Révélation. Inadmissible pour les catholiques, ce transformisme dessinait les lignes de fractures et engageait des appréciations divergentes, non seulement dans le rapport au passé, mais surtout dans les conceptions de l'humaine condition, donc de la société et de l'avenir.

Les philosophes et les novateurs en religion avaient hérité des Lumières en indivis la conviction dans le progrès de l'humanité par l'histoire et les croyances religieuses accompagnaient ce progrès : à chaque époque correspondait un système de croyance adapté, chacun se succédant dans une dynamique ascendante. Ce

85. Voir la conclusion de Louis Châtellier, Les espaces infinis et le silence de Dieu : science et religion, XVI ${ }^{e}$-XIX siècles, Paris, Aubier, 2003.

86. Loïc Rignol, Les hiéroglyphes de la nature : le socialisme scientifique en France dans le premier XIXe siècle, Dijon, Presses du réel, 2014.

87. Eugène Lerminier, «De l'encyclopédie à deux sous et de l'instruction du peuple », Revue des deux mondes, 1834, t. 1, p. 291.

88. Narcisse Cacheux, « Nouveau plan d'attaque de M. Lerminier contre la religion », Études ecclésiastiques, t. 2, 1833, p. 342-361. 
débat, qui avait déjà cours au XVIII ${ }^{\mathrm{e}}$ siècle, ne visait plus seulement à démontrer l'extension du domaine de la raison, mais touchait à la compréhension des édifices sociaux. Ceux-ci étaient périssables et emportaient avec eux leurs croyances. Si les novateurs radicaux, ou les illuminés, inventaient de toutes pièces les religions de l'avenir, l'élite savante préférait envisager la transformation des croyances anciennes. À la différence des cultes révolutionnaires, il n'était pas question de décréter une religion civique, mais plutôt de voir accoucher une religion nouvelle des transformations en cours de la société. La volonté humaine avait d'autant plus perdu de sa superbe que 1793 était l'objet d'une horreur assez générale. On scrutait donc le présent, à la lumière de l'expérience de l'humanité, et on attendait non sans anxiété l'avenir. Dans sa conférence sur le scepticisme, Jouffroy expliquait que si le christianisme n'était plus en mesure jouer le rôle historique qu'il avait tenu, parce qu'il ne pouvait plus répondre à l'ensemble des interrogations contemporaines, son « fond [était] trop vrai pour que cette grande religion disparaisse, comme l'a fait le paganisme; sa destruction est un rêve du $\mathrm{XVIII}^{\mathrm{e}}$ siècle, qui ne se réalisera pas; mais nul doute qu'elle ne doive subir une épuration et recevoir une forme nouvelle ». En 1834, Lerminier écrivait : « il est juste de dire que derrière le christianisme, il se prépare quelque chose $»^{89}$. L'année suivante, l'interrogation n'avait pas disparu dans les colonnes de la Revue des deux mondes: "la manière dont le christianisme se remettra à avoir prise sur la société de l'avenir, demeure voilée encore; et pour les esprits méditatifs les plus religieux, l'inquiétude du grand problème n'a pas diminué $»^{90}$. La Révélation était interprétée comme une loi sociale dont on ne savait pas trop comment devaient se réaliser toutes les promesses, mais qui restait, sous une forme plus ou moins intègre, le fondement moral de l'ordre. Les progrès de l'intelligence en rendaient la compréhension plus complète : la Révélation offrait une base solide, intangible donc rassurante, mais le catholicisme ne semblait n'être qu'une forme historique périmée de la Révélation. Avec ce christianisme philosophique et spiritualiste, aux multiples variantes, l’Église

89. Eugène Lerminier, «De l'enseignement des législations comparées », Revue des deux mondes, 1834, t. 3, p. 257.

90. Sainte-Beuve, "Poètes et romanciers modernes en France », Revue des deux mondes, 1835, t. 2, p. 290. 
voyait lui échapper son monopole de l'interprétation de la parole évangélique, d'où étaient alors expulsés par ailleurs la question des fins dernières et le salut.

Si beaucoup d'auteurs catholiques se félicitaient de ce que promettait «l'esprit du temps », ils considéraient évidemment qu'il ne s'agissait que d'une situation transitoire qui annonçait un retour vers l'Église. Dans toutes les revues, parmi les nombreuses pages consacrées à la philosophie, l'abbé Bautain connut un grand succès ; il fut même, entre 1833 et 1835 , un auteur à la mode. Il publia dans la France littéraire un article, fragment de sa Philosophie du christianisme (1835), qui doit faire figure de manifeste puisque, moins optimiste, il assimilait le mouvement religieux contemporain au panthéisme, le vrai mal du siècle, renouveau hérétique sous le couvert de spiritualisme qui présidait en fait à une sortie de la foi orthodoxe. Jusque-là, les revues catholiques, suivant le premier Lamennais et Mirari vos, condamnaient surtout les spéculations philosophiques au titre d'indifférentisme, puisqu'au fond elles considéraient que toutes les religions se valaient. L'accusation manquait un peu la cible puisque, d'une part, les croyances étaient soumises à la loi du progrès et ne se valaient donc pas, et que, d'autre part, le christianisme restait la référence. Bien plus cruciale était la défense qui s'arc-boutait sur le caractère surnaturel de l'action du christianisme parce qu'elle soutenait le rôle de la providence dans l'Histoire. Plus profond encore était le combat à propos de l'immutabilité du dogme et de la distinction entre les "principes éternels ", le progrès des connaissances et le progrès social, car il mettait en jeu des acceptions de l'humanité.

Il découlait évidemment de ces divergences des conceptions antagoniques de l'édifice social et de la fonction de la religion. Dans le sillage de l'apologétique développée au XVIII ${ }^{\mathrm{e}}$ siècle en

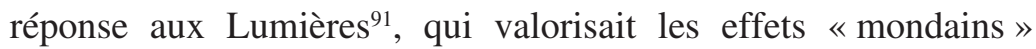
$\mathrm{du}$ catholicisme (bienfaits sociaux et individuels des vertus chrétiennes et de la croyance en l'au-delà), les Études religieuses exposaient le catholicisme comme la réponse aux interrogations d'une génération angoissée. Cette défense semblait pertinente face à des spéculations religieuses aux motivations «temporelles ».

91. Didier Masseau, Les ennemis des philosophes. L'antiphilosophie au temps des Lumières, Paris, Albin Michel, 2000. 
La Dominicale affichait de son côté un programme ambitieux, aux accents significatifs : " nous prenons les doctrines catholiques pour point de départ, et le bonheur de l'humanité pour but $\gg^{92}$. Le christianisme avait été dans l'histoire le principal agent de transformation, mais avec lenteur et prudence ; il irrigua lentement toutes les classes de la société. Le dogme, né de la parole du Christ, agissait insensiblement et la société évoluait sur cet axe. C'était proposer une théologie du progrès, sans révolutions. Que l'Église soit immobile au milieu du courant contemporain des idées prouvait seulement qu'elle conservait l'arche des vérités divines, tandis que les mouvements incessants de la philosophie montraient la vaine recherche d'une société déracinée de la tradition. C'était en revenir à la rupture générationnelle introduite par la Révolution ${ }^{93}$ : une génération que les mères - faute de prêtres avaient mal éduquée en religion; qui avait ensuite éprouvé tous les systèmes, toutes les expériences - comme le Jérôme Paturot de Reybaud devait bientôt éprouver tous les statuts sociaux; et arrivait en 1834, lasse, déçue, mais mûre pour revenir à la tradition que les travaux savants tendaient à valider. La quête d'autorité réhabilitait le catholicisme : "nous sommes en voie de retour vers l'unité, dont l'Église seule possède le principe et la règle », pouvait alors écrire La Dominicale ${ }^{94}$.

En définitive, l'encyclique de 1832 n'a pas étouffé les ferments de l'utopie mennaisienne, même si elle a provoqué le retrait à peu près complet des disciples de l'action publique : c'était le but de Mirari vos. Elle continua d'agir de manière plus diffuse, sans se mêler directement de politique, hors de l'influence du Maître et dans des milieux qui ne lui étaient pas directement attachés. Tous les sujets qu'avait brassés Lamennais depuis une dizaine d'années, où il avait placé la question religieuse au cœur de l'avenir de la société, connurent entre 1832 et 1835 une actualité plus poignante : le caractère mortifère du scepticisme, du matérialisme, de l'individualisme ; la nécessité sociale d'un magistère spirituel et d'un criterium de certitude issu de l'expérience de l'histoire; les attributs respectifs de la religion et de la philosophie ; la portée

92. «La religion comme puissance civilisatrice », La Dominicale, t. 1, 1833, p. 3.

93. Un article exemplaire : «Du mouvement religieux et des devoirs...»

94. « De l'anarchie des doctrines », La Dominicale, t. 1, 1833, p. 510. 
sociale de la Révélation ; le progrès, dans ses liens avec la tradition ou avec la providence, et, in fine, le peuple mythifié de 1830 comme agent historique de cette providence. On comprend mieux sous cet angle que ses contemporains l'aient assez unanimement rangé parmi les premiers écrivains de leur siècle.

Le pouvoir né de 1830, par ses relations avec l'Église catholique, avait en théorie dégagé le religieux de la question du gouvernement, mettant à jour une situation de tensions entre le processus «d'individuation des conduites religieuses ${ }^{95}$, qui découlait pour partie de ce «seuil de sécularisation », et le christianisme qui restait la matrice de la morale collective. Ces tensions ont été à l'origine des spéculations religieuses qui étaient moins d'ordre politique que d'ordre social. Il ne s'agissait pas d'anticipations des « religions séculières » dont a parlé Raymond Aron, car dans l'ordre spéculatif et savant comme dans l'ordre des hétérodoxies radicales, ce renouveau religieux conservait à son principe un rapport à la transcendance et à la tradition, dans des relectures plus ou moins radicales. Par ailleurs, ces spéculations débordaient les milieux du socialisme naissant étudiées d'abord par Henri Desroche ${ }^{96}$, et les catholiques entretenaient un dialogue avec ces novations qu'ils prenaient de haut, mais qui réintégraient finalement le catholicisme dans les débats intellectuels d'actualité. Les autorités romaines n'ignoraient pas ce mouvement des idées. L'internonce à Paris écrivait: «il est vrai que dans ce pays-ci existe un mouvement insolite, mais décidé, vers les idées religieuses, mouvement dont on pourrait, si les temps étaient calmes et réguliers, et avec beaucoup de prudence et de dextérité, tirer des résultats consolants. Mais [...] ce mouvement est vague, et une partie de ceux qui le soutiennent éprouvent bien un besoin de Religion, sans cependant avoir une idée claire de la Religion du Christ ${ }^{97}$. C'est à cette configuration que l'encyclique de 1834 vint mettre fin. Les Études religieuses cessèrent de paraitre dès 1834 . La Dominicale comme la Revue européenne ne durèrent que quelques mois de plus. Cette même année, Ballanche, pourtant habitué des pages de la France

95. Philippe Boutry, «Théologie de l'air du temps... », op. cit.

96. Citons : Henri Desroche, Les dieux rêvés. Théisme et athéisme en utopie, Paris, Desclée, 1972.

97. Dépêche de l'internonce Garibaldi, 9 mai 1834, Marie-Joseph Le Guillou et Louis Le Guillou (éd.), La condamnation...., op. cit., p. 467. 
littéraire, disparut de ses colonnes : l'éclectisme d'opinion voulu par son directeur laisse place à l'orthodoxie (l'abbé Flottes), comme le signale d'ailleurs la recension négative des Paroles qui vint corriger un premier article louangeur ${ }^{98}$, et finalement à l'effacement des débats religieux, comme dans la Revue des deux mondes. Des symptômes peuvent illustrer ce changement de conjoncture : en 1836, L'Écho de la Jeune France, à propos d'un ouvrage de l'abbé Caron qui tentait de concilier la raison générale «mennaisienne» et raison individuelle « cartésienne », saluait sa volonté « de relever le courage de ceux qui tremblaient d'aborder désormais la question de la certitude $»^{99}$ - vaine tentative ; en 1837, le sulpicien Boyer achevait le second tome de sa somme anti-mennaisienne par un tableau fort pessimiste du «mouvement religieux» qui suscitait chez lui surtout de la défiance ${ }^{100}$. Il est plus révélateur encore que l'abbé Gerbet, réglant ses comptes en 1838 avec son ancien maître, exposât les mêmes sentiments en appelant à la méfiance contre la sécularisation de la morale évangélique qui, moins franche que dans la polémique du XVIII ${ }^{\mathrm{e}}$ siècle, altérait les dogmes par des coïncidences choisies entre vérités de foi et philosophie ${ }^{101}$.

Le Saint-Siège continua de mettre bon ordre, à chaque bout du spectre philosophique, et bien plus nettement qu'avec Lamennais, en obtenant, en 1835, la rétractation de l'abbé Bautain, soupçonné de fidéisme; en condamnant la même année la philosophie des disciples du théologien Hermès, caractérisée par le rationalisme. Une conjoncture se refermait: Rome avait préservé dans la tourmente l'unité de l'Église ; l'ordre était rétabli en Europe; le gouvernement de Juillet semblait plus solidement établi après les lois de septembre 1835 et un nouvel équilibre était trouvé dans les relations avec l'Église qui renouait, bon an mal an, avec une entente cordiale.

À cet égard, Singulari nos, souvent interprétée à la lumière du seul cas Lamennais, prend une autre importance. En effet, bien

98. Jules Ollivier, «Paroles d'un croyant », La France littéraire, t. 14, 1834, p. 216-236.

99. L'Écho de la jeune France, 1836/1, p. 22.

100. Pierre-Denis Boyer, Défense de l'ordre social contre le carbonarisme moderne, Paris, Le Clère, 1837.

101. Philippe Gerbet, Réflexions sur la chute de M. de la Mennais, Paris, Au bureau de l'Université catholique, 1838, p. 50-53. 
qu'il soit seul visé directement, l'encyclique mit un coup d'arrêt, côté catholique, aux débats sur les relations du christianisme avec le progrès - les Annales de philosophie chrétienne se fixent pour longtemps dans la défense du traditionalisme le plus strict - et aux contaminations entre la tradition évangélique et un ordre social nouveau. Au fond, les deux encycliques encourageaient un même mouvement: elles invitaient de fait les catholiques au retrait de la vie politique et, paradoxalement, cette abstention participait d'une forme de sécularisation. Le cardinal Micara, bien introduit dans les milieux de la Curie, l'exprimait assez bien : «jamais l'Église ne parle contre les abus de pouvoir [...]. Pourquoi ne pas laisser la politique de côté, pour ne s'occuper que du salut des hommes ? ${ }^{102}$. Cette position arrangeait tous les gouvernements, spécialement en France, et sous ce point de vue l'affirmation intransigeante des années 1830 ne peut être comparée à celle de 1864 (Quanta cura et le Syllabus), ce qui explique aussi l'accueil polémique des deux encycliques sur le mode mineur. Les autorités romaines refusaient la double opération que tentaient les Paroles et qui attribuait au christianisme des finalités exclusivement temporelles. D'abord, l'opuscule ne s'adressait pas spécifiquement aux catholiques, mais tendait à recentrer l'explosion de religiosité sur la tradition chrétienne. Le second objectif était d'apposer à l'interrogation sur la fonction sociale de la religion le sceau de la Révélation, et d'y annexer la légitimité du peuple, conservatoire du passé et force de l'avenir. L'opération avait l'avantage d'apporter une caution religieuse attachée à la tradition et d'exorciser la peur d'arrachement au passé qui travaillait finalement les opinions, tout en projetant les promesses d'un avenir conforme aux lois du progrès pour des républicains frappés par la stérilité de l'éclair de Juillet. Les Paroles ne pouvaient être un ouvrage de «pure politique » comme le prétendait Lamennais.

La prudence de Rome, l'hésitation des disciples de Lamennais, le succès des Paroles, l'actualité des thèmes brassés par leur auteur, montrent qu'il exista dans une bonne partie des élites une hypothèque religieuse révolutionnaire. Cet « esprit de $1830 »$ se caractérise par le fait que les aspirations politiques et

102. Cité dans: Jean-René Derré, Littérature et politique dans l'Europe du XIX siècle, Lyon, PUL, 1986, p. 172 (correspondance d'Emmanuel d'Alzon). 
sociales surtout se démarquaient mal des interrogations religieuses. Paroxystique entre 1832 et 1835 , pétri d'attentes et rongé d'incertitudes, il révèle un «moment mennaisien », tant l'auteur des Paroles sembla pouvoir alors réagencer les aspirations de la période. Moment mennaisien aussi, parce que sa rupture avec Rome signa le passage du Christ du côté des barricades ${ }^{103}$ : une configuration politico-sociale qui chemine les années suivantes et donnera toute sa force en 1848. Charles de Ludre, député de la Meurthe, siégeant à l'extrême gauche, figurait en 1835 parmi les accusés du procès des insurgés d'avril 1834, mais se réfugia en Suisse. Son frère, étonné, le vit alors un Nouveau Testament en poche : « oui, mes idées sont bien changées, et non seulement les miennes mais celles de tous mes amis politiques, tellement que notre premier acte, si nous arrivions au pouvoir, serait de déclarer que la morale du christianisme serait la base de toutes nos lois : le parti voltairien est à jamais sans influence, il est dépassé par la portion spiritualiste du parti républicain ${ }^{104}$. Michelet suggère, sur un plus long terme, les reconfigurations politico-religieuses du XIX ${ }^{\mathrm{e}}$ siècle : dans le second tome de son Histoire de France, il écrivait en 1833 que le christianisme «peut changer de vêtement, mais périr, jamais; il se transformera pour vivre encore »; ce développement est absent dans l'édition de 1861.

sylvain.milbach@univ-smb.fr

103. Franck-Paul Bowman, Le Christ des barricades, 1789-1848, Paris, Cerf, 1987.

104. CG, t. VI, Benoît d'Azy à Lamennais, 20 février 1835. 